\title{
USE OF THE WHIRLIGIG PRINCIPLE FOR STABILIZING THE INITIAL STATES OF SOME CLASSIC AND QUANTUM SYSTEMS
}

\author{
V. A. Buts* \\ National Science Center "Kharkiv Institute of Physics and Technology", 61108 Kharkiv, Ukraine \\ Institute of Radio Astronomy of the National Academy of Sciences of Ukraine, 61002 Kharkiv, Ukraine
}

(Received June 15, 2020)

\begin{abstract}
It is shown that the whirligig principle can be used for stabilization of the initial states of some classical and quantum systems. This feature of the whirligig principle is demonstrated by simple examples. The most important result of this work is the proof of the fact that the stabilization of the excited states of quantum systems can be realized by acting not on the quantum system itself, but by acting on the states into which the system must go. Potentially, this result can be used to stabilize excited nuclear systems.
\end{abstract}

PACS: 03.65.Xp; 46.40.Ff

\section{INTRODUCTION}

The principle of whirligig was formulated in [1-5]. It turned out to be very simple, visual, effective. Let us briefly recall its main characteristics. The principle is based on the image of the whirligig. This image contains simple quantitative conditions for the implementation of stabilization of the initial states of systems. If the whirligig does not rotate and it is set upright, then it falls. The time of the fall of the whirligig can be considered the lifetime of the unstable state of the whirligig $\left(T_{L}\right)$. If the yule rotates and its rotation period $\left(T_{w}\right)$ is much shorter than the life time of the whirligig $\left(T_{L} \gg T_{w}\right)$, then the vertical position of the whirligig will be stable. It turned out that such a simple principle is suitable for stabilizing a large number of excited states of physical systems. As an example, we point out the stabilization (suppression) of plasma-beam instability, the suppression of the processes of decay of waves that propagate in plasma (including the stabilization of explosive instability). It turned out to be possible to suppress local instability (by the example of stabilization of the regular dynamics of the Lorentz system). In this paper, we consider some other physical systems (classical and quantum) for which the whirligig principle also turns out to be useful for stabilizing their initial states. In section 2 considers a fairly general classical system. In section 3 - quantum system. The most important result is the possibility of stabilizing the states of the quantum system when we will be acting not on the system itself, but on the states into which the system can go. Potentially, this 1998result can be useful for stabilizing nuclear processes such as, for example, beta decay.

\section{STABILIZATION OF THE ORIGINAL STATE OF THE CLASSICAL SYSTEM}

Let's consider a classical system whose vibrational properties contain a spectral component at a frequency. This feature of the system can be modeled by the equation of a linear oscillator:

$$
\ddot{q}_{1}+\omega^{2} q_{1}=0 .
$$

Let the system in question be at rest at the initial instant of time. Suppose that in addition to the system we are studying, there is another system whose spectrum also contains the frequency $\omega$. This second oscillatory system is excited at the initial time. Now let these two systems turn out to be connected with a small coupling coefficient $\left(h_{1} \ll 1\right)$. In this case, it is convenient to present the mathematical model of the complete system in the form:

$$
\ddot{q}_{2}+\omega^{2} q_{2}=-h_{1} q_{1}, \ddot{q}_{1}+\omega^{2} q_{1}=-h_{1} q_{2} .
$$

Due to the connection, the two systems interact. After the time $\left(T \sim \omega / h_{1}\right)$ the vibrational energy of the second system at a frequency will be transferred to the vibrational energy of the first system.

It may turn out that the oscillations of the first system with such a level of amplitude for one reason or another are unacceptable. In this case, one can use (to stabilize the initial state of the first system) the whirligig principle. For this, we introduce into system (2) an additional oscillatory system that oscillates at the same frequency $\omega$. This additional system is only

\footnotetext{
*Corresponding author E-mail address: vbuts@kipt.kharkov.ua
} 
connected with the second system. Moreover, the coupling coefficient between the second system and the additional system $\left(h_{2}\right)$ is much larger than the coupling coefficient between the first and second system $\left(h_{2} \gg h_{1}\right)$. As a result, a complete system of equations that describes the dynamics of these three physical systems (interacting at a frequency $\omega$ ) can be written as:

$$
\begin{gathered}
\ddot{q}_{1}+\omega^{2} q_{1}=-h_{1} q_{2}, \\
\ddot{q}_{2}+\omega^{2} q_{2}=-h_{1} q_{1}-h_{2} q_{3}, \\
\ddot{q}_{3}+\omega^{2} q_{3}=-h_{2} q_{2} .
\end{gathered}
$$

To analyze the solutions of system (3), we take into account that the main fast dynamics of this system (elements of this system) occurs at a frequency $\omega$. The presence of small bonds between the individual elements of the complete system $\left(h \ll \omega^{2}\right)$ allows you to search solution in the form:

$$
q_{i}=x_{i}(t) \cdot \exp (i \omega t) .
$$

Here $x_{i}(t)$ - are the slowly changing functions.

It is convenient to use the averaging method to find these functions. As a result, we obtain the following system of equation for determination these functions:

$$
i \dot{x}_{1}=x_{2} ; i \dot{x}_{2}=-\mu x_{3} ; i \dot{x}_{3}=-\mu x_{2} .
$$

Here $\mu=h_{2} / h_{1} \gg 1, \dot{x}=d x / d \tau, \tau=\left(h_{1} / \omega\right) t$. It can be seen that the dynamics of the second system obeys the equation:

$$
\ddot{x}_{2}+\left(1+\mu^{2}\right) x_{2}=0 .
$$

Taken in account that $\mu \gg 1$, the solutions of the system of equations (5) can be represented as:

$$
x_{2}=\cos (\mu \tau) ; x_{3}=i \cdot \sin (\mu \tau) ; x_{1}=\frac{i}{\mu} \sin (\mu \tau) \text {. }
$$

It can be seen from expression (7) that the oscillations of the first system now occur with a significantly lower amplitude than before the introduction of the third oscillatory system. Thus, the presence of a third additional oscillatory system significantly limits the impact (influence) of the second oscillatory system on the first one.

\section{STABILIZATION OF QUANTUM SYSTEMS}

Let's consider a multi-level quantum system, which is described by the Hamiltonian:

$$
\hat{H}=\hat{H}_{0}+\hat{H}_{1}(t) \text {. }
$$

The second term on the right-hand side describes the disturbance. The wave function of system (8) obeys the Schrodinger equation, the solution of which will be sought in the form of a series of eigenfunctions of the unperturbed system:

$$
\psi(t)=\sum_{n} A_{n}(t) \cdot \varphi_{n} \cdot \exp \left(i \omega_{n} t\right),
$$

where $\omega_{n}=E_{n} / \hbar ; i \hbar \frac{\partial \varphi_{n}}{\partial t}=\hat{H}_{0} \varphi_{n}=E_{n} \cdot \varphi_{n}$. We substitute (9) into the Schrodinger equation and in the usual way we obtain a system of coupled equations for finding complex amplitudes $A_{n}$ :

$$
i \hbar \cdot \dot{A}_{n}=\sum_{m} U_{n m}(t) \cdot A_{m}
$$

where $U_{n m}=\int \varphi_{m}^{*} \cdot \hat{H}_{1}(t) \cdot \varphi_{n} \cdot \exp \left[i \cdot t \cdot\left(E_{n}-E_{m}\right) / \hbar\right]$. $d q$. We consider the simplest case of biharmonic perturbation $\hat{H}_{1}(t)=\hat{U}_{0} \cdot \exp \left(i \omega_{0} t\right)+\hat{U}_{1} \cdot \exp \left(i \omega_{1} t\right)$. Then the matrix elements of interaction will acquire the following expression:

$$
U_{n m}=V_{n m} \exp \left\{i \cdot t \cdot\left[\left(E_{n}-E_{m}\right) / \hbar+\Omega\right]\right\} .
$$

Here $V_{n m}^{(k)}=\int \varphi_{n}^{*} \cdot \hat{U}_{k} \cdot \varphi_{m} \cdot d q, \Omega=\left\{\omega_{0}, \omega_{1}\right\}$.

Let's consider the dynamics of a three-level system $(|0\rangle,|1\rangle,|2\rangle)$. We assume that the frequency of the external disturbance and the eigenvalues of the energies of these levels satisfy the relations:

$$
\begin{aligned}
& m=1, n=0, \hbar \omega_{0}=E_{1}-E_{0} ; m=2, n=0, \\
& \hbar\left(\omega_{0}+\omega_{1}\right)=E_{2}-E_{0}, \hbar \omega_{1}=E_{2}-E_{1} .
\end{aligned}
$$

Relations (12) indicate the fact that the frequency $\omega_{0}$ of the external disturbance is resonant for transitions between the zero and first levels, and the frequency $\omega_{1}$ is resonant for transitions between the first and second levels. Using these relations in system (10), we can restrict ourselves to three equations:

$$
i \dot{A}_{0}=A_{1}, i \dot{A}_{1}=A_{0}+\mu A_{2}, i \dot{A}_{2}=\mu A_{1} .
$$

It is convenient to represent the system of equations (13) in a slightly different form:

$$
\ddot{A}_{1}+\Omega^{2} A_{1}=0, i \dot{A}_{0}=A_{1}, i \dot{A}_{2}=\mu A_{1},
$$

where $\Omega_{2}=\left(1+\mu^{2}\right)$.

The scheme of energy levels in this case is presented in Figure.

In (13) for simplicity and convenience we put $V_{12}=V_{21} ; V_{10}=V_{01} ; \dot{A}_{i}=d A_{i} / d \tau, \tau=V_{10} \cdot t / \hbar$. In addition, a parameter $\mu=V_{12} / V_{10}$ has been entered. Consider the most interesting special cases.

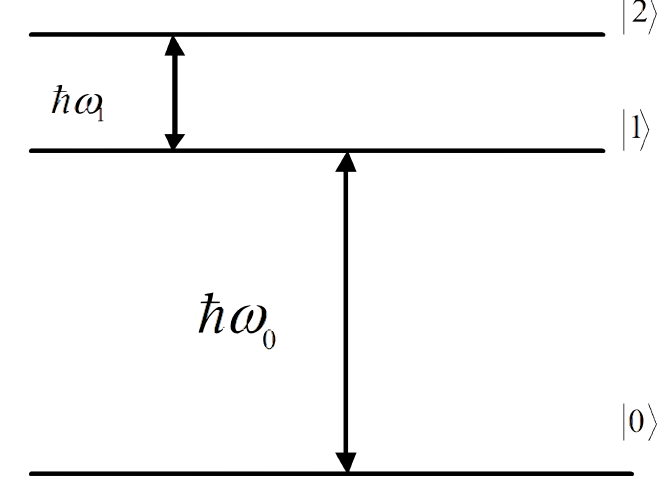

The scheme of energy levels 
Let, at the initial moment of time $(t=0)$, the system under consideration be at the first excited level. Then, as is easy to see, the solutions of system (13) are the functions:

$$
\begin{gathered}
A_{0}=\frac{1}{i \cdot \Omega} \sin (\Omega \cdot t), A_{1}=\cos (\Omega \cdot t), \\
A_{2}=-i \sin (\Omega \cdot t) .
\end{gathered}
$$

It follows from solution (14) that the larger the parameter $\mu$, the less probability it will be that the system will switch from an excited state to an unexcited $\left(A_{0}\right)$ stationary state. A few words should be said about the parameter $\mu$. Physically, this parameter determines the ratio of the number of quanta of the low-frequency disturbance, which is responsible for the transitions between the first and second levels to the number of quanta of the high-frequency disturbance, which determines the transitions between the first and zero levels. The larger this ratio, the less probability it will be that the excited system goes into an unexcited state [6]. Excited, we consider the first and second levels.

We will solve the problem with the initial conditions $\left|A_{0}(0)\right|^{2}=1,\left|A_{1}(0)\right|=\left|A_{2}(0)\right|=0$, i.e. at the initial moment of time, the system is in the main unexcited level, and the fast dynamics is carried out by those levels to which the system from the initial level should go under the influence of an external RF disturbance. In this case, the expressions for the amplitudes of the wave functions take the form:

$$
\begin{gathered}
A_{1}=-(2 i / \Omega) \sin (\Omega t), A_{0}=1-\frac{1}{\Omega^{2}}[1-\cos (\Omega t)] \\
A_{2}=\frac{2 \mu}{\Omega^{2}}[1-\cos (\Omega t)] .
\end{gathered}
$$

An important and somewhat unexpected result follows from the form of solutions (15). It consists in the fact that if the parameter $\mu$ is enough large, then despite the fact that the external stabilizing influence does not affect the ground state of the system, however, this state is stable. Thus, it is possible to stabilize the unstable states of quantum systems not only by acting on the states in which the quantum system is located, but by acting only on those states (making them dynamic) into which the system must go. This result is qualitatively different from the quantum Zeno effect.

An even more interesting case is when the initial state of the system is an excited state. Under the action of an external resonant perturbation, the system under consideration should go into another state with lower energy. However, using the principle of whirligig, one can stabilize this excited state. We show this result. Let the system be in the upper excited state $A_{2}(0)=1$ at the initial moment of time. Between matrix elements there are such ratios:

$$
\begin{gathered}
V_{01}=V_{10} \gg V_{12}=V_{21} ; \mu=V_{01} / V_{12} \gg 1 ; \\
A_{0}(0)=A_{1}(0)=0 ; \tau=V_{12} \cdot t / \hbar .
\end{gathered}
$$

Taking into account these relations, the system of equations (13) takes the form:

$$
i \dot{A}_{0}=\mu A_{1} ; i \dot{A}_{1}=\mu A_{0}+A_{2} ; i \dot{A}_{2}=A_{1} .
$$

The solutions of these equations are the functions:

$$
\begin{aligned}
& A_{0}=\frac{\mu b}{i \Omega} \cos \Omega t ; A_{1}=b \sin \Omega \tau ; \\
& A_{2}=1-\frac{b}{i \Omega} \cos \Omega \tau ; b \rightarrow 0(1 / \mu) .
\end{aligned}
$$

It is seen that the probability of the system being in the excited state is the closer to the initial state (excited), the greater the coefficient $\mu$. This case is especially interesting when we cannot influence on the system we want to stabilize with an external disturbance. However, we can change the nature of those energy levels to which an excited system can go (transform them into dynamic levels). Potentially, this situation may arise when trying to stabilize some excited nuclear states, for example, to suppress the beta-decay process.

\section{CONCLUSIONS}

Let's state the most important results of the work:

- First of all, the examples discussed above show that the principle of whirligig is really very simple and effective. It can be used both to stabilize classical systems and quantum systems.

- The above examples have been simplified as much as possible. This was done specially. There was desire to make the results as accessible as possible for understanding and for reproducing these results. In the considered models, for example, spontaneous emission was not taken into account anywhere. We limited only by induced processes. It is clear that most of the more complex models should in their variants receive results that are similar to the results obtained above.

- Special attention deserves the results, which show that it is possible to stabilize the state of quantum systems without affecting these states themselves, but by changing the dynamics of the states into which these systems must go.

\section{References}

1. V.A.Buts. Stabilization of instable states // MIKON. 2014, 20th International Conference on Microwaves, Radar and Wireless Communications. June 16-18, Gdansk, Poland. 2014, p.681685 .

2. V.A.Buts. Mechanisms for increasing the frequency and degree of coherence of radiation. Overview // Problems of Theoretical Physics. Series "Problems of Theoretical and Mathematical Physics. Scientific Works". KhGU, 2014, N1, p.82-247. 
3. V.A.Buts. Kapitsa peniulum and principle of whirligig // Problems of Atomic Science and Technology. Series "Plasma Physics". 2015, N4(98), p.237-240.

4. V.A. Buts. Quantum Zeno effect, Kapitsa pendulum and Whirligig principle. Comparative analysis // East European Journal of Physics. 2015, v.2, N4, p.4-20.
5. V.A.Buts. Quantum Zeno Effect, Kapitsa Pendulum and Spinning Top Principle // http://arxiv.org/abs/1711.01071.

6. V.M.Kuklin. Selected chapters (theoretical physics). Kharkiv: "KhNU named after V.N. Karazin", 2018, 212p.

\title{
ИСПОЛЬЗОВАНИЕ ПРИНЦИПА ЮЛЫ ДЛЯ СТАБИЛИЗАЦИИ ИСХОДНЫХ СОСТОЯНИЙ НЕКОТОРЫХ КЛАССИЧЕСКИХ И КВАНТОВЫХ СИСТЕМ
}

\author{
B. A. Буu
}

Показано, что принцип юлы может быть использован для стабилизации исходных (начальных) состояний некоторых классических и квантовых систем. Такая особенность принципа юлы продемонстрирована на простых примерах. Наиболее важным результатом работы является доказательство факта, что стабилизацию возбужденных состояний квантовых систем можно реализовать воздействием не на саму квантовую систему, а воздействуя на состояния, в которые система должна перейти. Потенциально этот результат может быть использован для стабилизации возбужденных ядерных систем.

\section{ВИКОРИСТАННЯ ПРИНЦИПУ ДЗИГИ ДЛЯ СТАБІЛІЗАЦІЇ ПОЧАТКОВИХ СТАНІВ ДЕЯКИХ КЛАСИЧНИХ І КВАНТОВИХ СИСТЕМ}

\author{
B. O. Буи
}

Показано, що принцип дзиґи може бути використаний для стабілізації вихідних (початкових) станів деяких класичних і квантових систем. Така особливість принципу дзиги продемонстрована на простих прикладах. Найбілыш важливим результатом роботи є доказ факту, що стабілізацію збуджених станів квантових систем можна реалізувати впливом не на саму квантову систему, а впливаючи на стани, в які система повинна перейти. Потенційно цей результат може бути використаний для стабілізації збуджених ядерних систем. 